\title{
Historia global o las geografías del pasado. Implicaciones de la perspectiva global y geográfica en la escritura de la historia

\author{
Global History or the Geographies of the Past: Implications of a
} Global and Geographical Perspective in the Writing of History.
}

\author{
Francisco Javier Navarro Jiménez \\ Universidad Complutense de Madrid \\ franna01@ucm.es
}

\section{Resumen}

La historia global es un campo de estudios emergente. En la aproximación al pasado desde esta perspectiva, el giro territorial y la escala de la larga duración son elementos centrales, con lo que ello supone de solapamientos metodológicos y epistemológicos con otras disciplinas, sobre todo con la geografía. Esta perspectiva ofrece abundantes beneficios, pero también se deben considerar los riesgos que supone. A través de ejemplos concretos de obras escritas desde este campo, el artículo discute la vigencia de conceptos como globalización y ecúmene, pero también cuestiones metodológicas como la larga duración y el determinismo geográfico. Se pretende con ello identificar posibilidades, fortalezas y riesgos en la escritura de la historia global.

\section{Palabras clave}

Historia global, geografía, territorio, larga duración, solapamientos metodológicos.

\begin{abstract}
Global history is an emergent field of study today. To apprehend the past from a global perspective, territorial turn and longue durée time scale become pivotal concepts, with the corresponding methodologic and epistemological overlaps with other disciplines, especially geography. Many benefits can be obtained from this perspective, but there are also risks that need to be considered. Through specific examples of works written from this field, this article examines the validity of concepts of globalization and ecumene, and discusses methodologic aspects related to the longue durée and geographic determinism. The ultimate purpose of it is to identify possibilities, strengths and risks in the writing of global history.
\end{abstract}

\section{Key Words}

Global history, geography, territory, longue durée, methodologic overlaps. 


\section{Introducción}

La perspectiva global en la escritura de la historia se ha venido desarrollando de manera notable a partir de las dos últimas décadas del siglo XX. Durante este tiempo, los objetos de estudio analizados y las metodologías empleadas por la llamada global history se han tornado atractivas no solo para los historiadores en su labor académica, sino también dentro de la didáctica de los programas de estudio universitarios. Eso ha permitido la emergencia y paulatina consolidación de esta perspectiva en unos tiempos en los cuales existe una mayor apertura a otras historiografías, y ya no solo a las de escala nacional. Aunado a eso, se debe tomar en cuenta la inquietud de algunos historiadores por romper con el paradigma de la historiografía política más tradicional, así como con la visión sobreespecializada de la microhistoria. Estas perspectivas, que durante las últimas décadas no habían ofrecido explicaciones suficientes sobre fenómenos particulares del pasado, deben ser revisadas hoy -en especial por la fuerte correlación que guardan con nuestro presente-, forzando su abordaje metodológico a la luz de las escalas geográficas internacional y global. $^{1}$

En el contexto descrito, este artículo discute algunos aspectos epistemológicos y metodológicos a través de ejemplos concretos de historiografías escritas desde la citada perspectiva. El objetivo será mostrar algunas de las posibilidades, fortalezas y riesgos que se pueden encontrar en el emergente campo de la historia global. Debido a su especial relación con la ciencia de la geografía, nuestro análisis estará caracterizado por la cuestión espacial y territorial, inherente a los estudios históricos globales. Los aspectos que se tratarán son dos, a saber: el primero de ellos se refiere a las propuestas y explicaciones alternativas, acerca de los orígenes de las actuales condiciones de globalidad. Tales explicaciones han surgido desde el campo de estudio de la historia global en respuesta a la idea hegemónica de otras disciplinas, de una globalidad contemporánea construida tan solo durante las últimas décadas del siglo XX. En ese sentido, los trabajos de Jürgen Osterhammel y Niels P. Peterson; ${ }^{2}$ Janet L. Abu-Lughod; ${ }^{3}$ así como Stewart Gordon, ${ }^{4}$ son obras que nos ofrecen interesantes ejemplos para analizar la propuesta historiográfica sobre la globalidad y los sistemas-mundo.

El segundo aspecto que aquí se pondrá en discusión se refiere a las particularidades metodológicas que se adoptan y se desarrollan durante la escritura de la historia desde la perspectiva global. Específicamente, nos referimos al uso de la escala temporal de la larga duración vinculada al cambio de escala espacial necesario en la aproximación a la historia

\footnotetext{
${ }^{1}$ David Armitage y Jo Guldi, “Le retour de la longue durée: une perspective anglo-americaine”, Annales, 70 année, 2 (2014).

${ }^{2}$ Jürgen Osterhammel y Niels P. Peterson, Globalization: A Short History (Princeton: Princeton University Press, 2005).

${ }^{3}$ Janet Abu-Lughod, Before European Hegemony: The World System A.D. 1250-1350 (New York: Oxford University Press, 1989).

${ }^{4}$ Stewart Gordon, When Asia Was the World (Cambridge Mass: Da Capo Press, 2008).
} 
global. Por otra parte, discutiremos la apertura de estas historiografías globales frente a las fuentes y las explicaciones basadas en categorías desarrolladas por ciencias como la economía, la geografía o la biología. Finalmente, se discutirá sobre los riesgos que dicha adopción metodológica puede implicar en estas historiografías, al ofrecer explicaciones hasta cierto punto deterministas. Para ello, revisaremos las obras de Kenneth Pomeranz, ${ }^{5}$ William McNeill ${ }^{6}$ y Jared Diamond. $^{7}$ Estos trabajos ofrecen interesantes propuestas historiográficas, que discutiremos, para comprender el alcance y los límites de los intercambios metodológicos entre la historia y otras disciplinas, especialmente con la geografía.

\section{Globalidad, ecúmene y mundialización: entre historia y geografía}

Globalization: A Short History, de los historiadores Jürgen Osterhammel y Niels Peterson, se ha convertido en una obra de referencia dentro de la disciplina para debatir sobre la componente histórica del proceso de globalización. Sin duda es un buen punto de partida para discutir un concepto que en los últimos años se ha tornado central para la historia global, y ello por dos razones: la primera de ellas, y la más evidente, es la actualidad del tema en el contexto de las sociedades hiper-conectadas. En ese sentido, proponer y debatir la globalización a partir de los estudios históricos también ha generado nuevas aproximaciones al fenómeno que nos llevan a pensarlo como un proceso histórico existente desde hace ya varios siglos, y no solo como un contexto dado durante el siglo XXI. De ahí la relevancia del debate no solo para los historiadores, sino también para quienes desde otras disciplinas y ciencias sociales se interesan por el tema con la necesaria apertura que nuestros tiempos demandan.

La segunda razón por la cual el debate sobre lo global ha tomado centralidad en la historia es la necesidad intrínseca a su estudio de aproximarse a los conceptos y métodos desarrollados por otras disciplinas, con el objetivo de reforzar las explicaciones sobre las actuales condiciones mundiales, pero siempre desde la perspectiva histórica. En la obra de Osterhammel y Peterson la globalización se entiende como un fenómeno dinámico y heterogéneo en el tiempo, donde se desarrollan, se concentran y se incrementan de manera importante las relaciones de integración entre diversas regiones del mundo a través de redes y esferas de contacto con relativa intensidad y frecuencia. Estas formas de integración pueden originarse y estructurarse a través de, por ejemplo, la capacidad de dominación política y militar de los imperios; las relaciones comerciales; la difusión de credos y doctrinas religiosas; la migración masiva y las diásporas; así como por la difusión de diversas pautas culturales. ${ }^{8}$

\footnotetext{
${ }^{5}$ Kenneth Pomeranz, The great Divergence: China, Europe, and The Making of The Modern World Economy (Princeton: Princeton University Press, 2000).

${ }^{6}$ William McNeill, Plagues and Peoples (Garden City, NY: Anchor Press, 1976).

${ }^{7}$ Jared Diamond, Guns, Germs and Steel: The Fates of Human Societies (New York: W.W. Norton \& Co., 1999).

${ }^{8}$ Jürgen Osterhammel y Niels P. Peterson, Globalization, 13-30.
} 
Es importante señalar que estos patrones de integración no son estáticos ni en el tiempo ni en el espacio, y que tampoco son un fenómeno propio de las postrimerías del siglo XX. Por el contrario -y en este sentido radica la principal aportación de los autores y su mirada historiográfica sobre el concepto de globalización-, las diferentes formas y patrones de integración entre diversos territorios y sociedades, como las que observamos actualmente, también es posible encontrarlos en otros momentos de la historia de las sociedades humanas. En ese sentido, los autores sitúan los inicios del actual estado de las relaciones de globalidad alrededor del año 1500. Aquel contexto estaba marcado por el fin de la Baja Edad Media y por la alborada de los grandes descubrimientos geográficos que tuvieron lugar gracias al desarrollo de las técnicas cartográficas y de la navegación transoceánica.

En el contexto, los autores ponen al descubierto el andamiaje de redes y esferas de contacto sobre las cuales se erige y oscila el actual fenómeno de globalización. Esta tarea se realiza tomando en cuenta los periodos de menor frecuencia y tenue intensidad entre dichas relaciones y contactos, lo que se describe como “de-globalización”. Sin embargo, se da especial atención a los procesos históricos precisos que determinaron en mayor medida el curso de la actual globalidad, entre ellos: la llegada de europeos al continente americano y el comienzo del contacto humano entre este último continente, Europa, África y Asia; la triangulación mercantil de bienes, mercancías y esclavos entre Europa, África y América, durante el siglo XVII y XVIII; así como la explotación, traslado e intercambio de la plata que establecieron por primera vez en la historia una red de comercio global durante el siglo XVIII.

Un segundo periodo identificado por los autores es aquel que va del año 1750 a 1880, y bajo el cual el mundo occidental registró dos grandes procesos que modelaron de manera importante las condiciones de globalidad: la Revolución industrial y la Revolución francesa. Estas dos revoluciones de finales del siglo XVIII sentaron el precedente para posteriores formas de integración mundial a través del imperialismo, la industrialización, el libre comercio, así como la difusión de las ideas sobre la construcción e integración de la figura geopolítica del Estado-nación. Sin embargo, también en este periodo, especialmente a finales del siglo XIX, surgieron las primeras crisis a gran escala derivadas de la condición global de la economía durante la época.

Ya para la primera década de siglo XX, se vivieron condiciones de integración global que aglutinaban diversas formas y esquemas. Sin embargo, la llegada de la primera y segunda guerras mundiales fueron determinantes en el deterioro de estas condiciones. No fue sino hasta la década de los setenta, cuando esas condiciones de integración en sus diversas formas volvieron a reconstruirse y a parecerse cada vez más a las redes y esferas actuales en las que buena parte de la población mundial interacciona a día de hoy.

Bajo esa propuesta de globalidad, en la obra de Osterhammel y Peterson nos interesa rescatar dos ideas clave que relativizan el fenómeno y que además nos permitirán ir más allá del siglo XV en el análisis de los sistemas-mundo: la primera de ellas se refiere a la cuestión temporal; es decir, la globalidad es puesta en discusión como un fenómeno 
dinámico temporalmente y no como un acontecimiento estático durante un breve periodo de tiempo. En este sentido, la globalidad desde los estudios históricos se convierte en un objeto de estudio aprehensible solo a través de la escala temporal de la larga duración. En segundo lugar, la globalidad no incluiría de manera forzosa la integración espacial de todo nuestro mundo conocido. Al contrario, y partiendo desde la historia, es posible hablar solo durante ciertos periodos de tiempo de redes de globalidad tejidas a partir de la integración parcial del mundo o de algunas regiones específicas.

Esta última idea, sin duda, nos hace pensar en la noción de “ecúmene”, aunque no de la forma precisa como la utilizaron los antiguos geógrafos griegos. El sentido del concepto que nos parece más adecuado es aquel que se reinterpretó en el seno de la geografía humana francesa moderna, a finales del siglo XIX y durante la primera mitad del XX. Max Sorre, discípulo del Paul Vidal de La Blache, describe la ecúmene como el mundo reconocido e interpretado a través de, por ejemplo, la cartografía y las ideas que los diferentes pueblos y culturas elaboran y transmiten como parte de su visión de la tierra habitada. ${ }^{9}$ Aludiendo al historiador Edmundo O’Gorman, diremos también que los límites de esta ecúmene se encontrarían determinados, en primer lugar, por un periodo de tiempo específico a través del cual toma una vital relevancia la interpretación y el horizonte cultural de los pueblos sobre su mundo; y por otra parte, por el alcance territorial de sus redes culturales, del comercio, de la política y de la dominación militar. ${ }^{10}$ En ese sentido, podríamos hablar por ejemplo de la ecúmene euroasiática considerada como tal por las diferentes culturas y naciones que la integraron hasta antes del siglo XV. ${ }^{11}$

La discusión sobre este concepto u otros relativos a la idea de la globalidad es muy antigua. Ya en tiempos de las conquistas romanas sobre los territorios del oriente griego, durante el siglo I a.C., Estrabón discernía en su obra Geografía sobre las condiciones geográficas y culturales que deberían tomarse en cuenta al momento distinguir los límites del Orbe -o los confines globales-. El geógrafo nacido en Amasya, al norte de la Península de Anatolia, discutía con sus predecesores y coetáneos acerca de la necesidad de incorporar al Orbe a los pueblos considerados bárbaros, debido a que estos habían desempeñado un papel dentro de la historia de la conformación de las redes del mundo antiguo. Por ejemplo, se debatía acerca de la inclusión cartográfica del mundo indio y de sus confines territoriales, relatados por los ejércitos de Alejandro Magno tres siglos antes. ${ }^{12}$

Así, la discusión ha llegado hasta nuestros tiempos, sea a través de historiadores contemporáneos como Osterhammel y Peterson, o gracias a geógrafos como Jacques Lévy, quien se refiere a la mondialisation no como un estado, sino como un proceso con contenido geográfico, solo accesible a través del análisis temporal. Citando a Braudel, el mismo geógrafo nos insiste en la pertinencia de releer la historia de la mundialización de la humanidad bajo la perspectiva geohistórica. Esta mundialización, sea contemporánea o una

\footnotetext{
9 Max Sorre, L'Homme sur la terre (París: Hachette, 1961), Cap.1.

${ }^{10}$ Edmundo O’Gorman, La invención de América (México: Fondo de Cultura Económica, 1958), Caps. 2 y 3.

${ }^{11}$ William MacNeill, "The Changing Shape of Worl History”, History and Theory, vol. 34, 2 (1995): 8-26.

${ }^{12}$ Estrabón, Geografía I (Barcelona: RBA Coleccionables, 2008), Libro II.
} 
relectura del mundo antiguo, es una realidad compleja donde sus actores piensan, hablan y discuten sobre ella, al mismo tiempo que la construyen y la practican. Pero sin duda la idea que mejor se incorpora a nuestra discusión sobre globalidad y ecúmene, es aquella en la que la mundialización pasa, de representar un simple contexto histórico, a convertirse en un paradigma de referencia temporal, espacial y cultural definido por los mismos pueblos y culturas que lo aprehenden cognitivamente. ${ }^{13}$

En una tónica muy similar, en los orígenes históricos del análisis de sistemas-mundo, Immanuel Wallerstein pone en claro los conceptos de tiempo y espacio sobre los que deberían analizarse dichos sistemas. Para este historiador, ambos conceptos son una sola realidad en constante evolución. El proceso de construcción del sistema-mundo pasa de ser un hecho supuestamente consumado, a una realidad social que se modifica constantemente y que por tanto los convierte en sistemas históricos. Estos sistemas históricos de organización mundial son una paradoja para el historiador que solo podrá ser analizada a la luz de los conceptos de tiempo-espacio, pero también a través de la delicada y temporal operación de abolición de las fronteras interdisciplinarias. ${ }^{14}$ Esta es la razón por la que la discusión adquiere particular relevancia entre geógrafos e historiadores, tomando como premisa que el espacio es el objeto de los primeros, y el tiempo el de los últimos.

\section{El mundo euroasiático}

A partir de esas primeras nociones sobre lo global, diremos que los trabajos de Janet L. Abu-Lughod, Before European Hegemony, y de Stewart Gordon, When Asia Was the World, describen el mundo euroasiático previo al siglo XVI como una macro-región de escala intercontinental en la que se construyó una "globalidad ecuménica”. ${ }^{15}$ Esto se logró a través de complejas relaciones asentadas en el comercio, la política, la religión y las artes. Aunque las fuentes y el método que utilizaron los autores en sus respectivos trabajos son muy diferentes, una constante en ambas obras es la función desempeñada por las redes políticas, los centros urbanos, las rutas comerciales y los templos religiosos; que sirvieron como nodos territoriales a través de periodos temporales de larga duración en la interconexión de las diversas regiones del mundo euroasiático.

En ese sentido, When Asia Was the World es una historia que intenta reconstruir el mundo asiático a través de un largo periodo de tiempo: desde el siglo VII y hasta el año 1500. El hilo conductor de esta historia son las relaciones y redes que el autor presenta dentro de los relatos de nueve personajes que circularon por las diferentes regiones de aquella ecúmene, entre el Levante y el extremo oriental de Asia. Estos personajes son la fuente principal que le da coherencia a un mundo antiguo caracterizado por la construcción y el mantenimiento de todo tipo de redes, las cuales articularon de manera funcional las

\footnotetext{
13 Jacques Lévy, “Geografía y mundialización”, en Daniel Hiernaux y Alicia Lindón (dirs.), Tratado de Geografía Humana (México: Anthropos; UAM-Iztapalapa, 2006), 273-8.

${ }^{14}$ Immanuel Wallerstein, Análisis de sistemas-mundo. Una introducción (México: Siglo XXI, 2005), $13-39$.

${ }^{15}$ El término "globalidad ecuménica” es una aseveración mía a partir de lo expuesto en las líneas anteriores, no de los autores de las obras.
} 
grandes regiones asiáticas. Tales redes comerciales, religiosas, artísticas y políticas, son descritas como el componente fundamental en la estructuración del extenso territorio del mundo asiático antiguo, mucho antes de la hegemonía mundial europea, la cual comenzó a manifestarse a partir de la época de los grandes descubrimientos geográficos.

En ese mundo asiático, que se extendió temporalmente durante prácticamente todo el medioevo europeo, las instituciones religiosas aparecen como agentes centrales de las diversas culturas orientales. Estos agentes fueron capaces de estructurar el territorio a través de los espacios destinados a la formación de monjes y al culto religioso. Pero también fueron fundamentales para la generación del conocimiento y para su difusión por toda Asia. Al mismo tiempo, el nacimiento de las dinastías imperiales, sus cortes e instituciones, jugaron un papel fundamental en la consolidación de la certeza política y la seguridad dentro de las rutas comerciales que atravesaban los más diversos climas, cordilleras, mares y desiertos. Estos territorios, que por mucho tiempo se pensaron distantes y poco interconectados, lograron constituirse en un mundo global a través del paso de casi nueve siglos, en los cuales, como hemos visto, fueron diversas las esferas de interacción que tuvieron que aparecer y volverse dinámicas en tiempo y espacio.

En una tónica muy similar, pero con fuentes y método diferentes, el trabajo de Janet Abu-Lughod, Before European Hegemony, nos introduce en la ecúmene euroasiática entre el año 1250 y 1350 para mostrar la existencia de un sistema-mundo donde interaccionaban la Europa occidental y China a través del puente territorial y cultural del Próximo Oriente. Este sistema lograba consolidarse principalmente a través de los intercambios económicos y políticos entre las tres regiones, pero principalmente en forma de proceso o sucesión, y no de manera directa. Durante estos cien años, las rutas comerciales gozaron de cierta estabilidad y seguridad propiciada por la paz que el Imperio mongol había construido a largo de todas sus conquistas hacia el sur y el oeste del continente asiático, lo cual permitió la formación de este sistema-mundo basado en el traslado de mercancías, la administración territorial y la tolerancia religiosa. Una de las características principales en la conformación de estas redes fue el papel hegemónico que jugaron las grandes ciudades de esta macroregión, en su papel de nodos urbanos donde confluían viajeros, mercancías y mercaderes, cortes reales y el poder político.

Estas condiciones, que generaron un sistema de interacción entre regiones -según la autora-, es posible entenderlas como el estadio previo al capitalismo desarrollado en Europa a partir del siglo XVI, el cual se fundó sobre los escombros del sistema-mundo euroasiático, consolidado entre finales del siglo XIII y durante la primera mitad del XIV. El factor que debilitó y finalmente rompió las esferas de interacción entre estas grandes regiones fue la subdivisión del Imperio Mongol entre los descendientes del Kublai Kan a principios del siglo XIV. Esta fragmentación dinástica, dio inicio a una época de incertidumbre y subsecuente declive del comercio en los territorios donde se localizaban las diversas rutas y ciudades que lo mantenían en funcionamiento.

Por otra parte, la difusión de la peste negra a través de Eurasia y hasta el Occidente de Europa terminó por romper las redes culturales y de comercio secular. Esto derivó en un 
aislamiento entre regiones durante los siguientes siglos que generó la falsa idea, según la autora, de que Europa fue el centro del desarrollo de las condiciones del capitalismo moderno. Finalmente, Abu-Lughod propone que dentro del actual sistema mundial basado en el capitalismo moderno, podría llegar a generarse un equilibrio de fuerzas y hegemonía entre los diversos centros productivos mundiales, algo muy parecido a lo que ella misma describió durante el siglo de paz mongólica.

Aunque entre ambas historiografías existen grandes diferencias, sobre todo en lo referente a las fuentes y al método analítico, entre ellas discurre una idea central constante: la de una ecúmene euroasiática previa al mundo moderno que construyó y mantuvo relaciones de globalidad bien definidas a través de diversas esferas, las cuales, a diferencia del mundo global de nuestro presente, tenían como único referente de acción el territorio. En él, los pueblos de la época manifestaron su cultura de diversas maneras y produjeron grandes nodos de comunicación en forma de ciudades y extensas vías de comunicación entre las que se conformaron las redes económicas del comercio, del poder político y militar. La ecúmene euroasiática logró materializarse en buena medida gracias a la difusión de las ideas, del conocimiento y de la religión que algunos imperios -unos más tolerantes que otros-, permitieron a todo lo largo de sus territorios y de su tiempo.

En ese sentido, finalmente, valdría la pena repensar desde la historia la noción de globalidad. Parece pertinente su reflexión, no como un concepto aplicado anacrónicamente, sino como la descripción de un determinado sistema dinámico, donde las relaciones de todo tipo se establecieron y se desarrollaron durante largos periodos de tiempo en el pasado. Por otra parte, también valdría la pena replantear la idea de la ecúmene. Utilizada por los historiadores y los geógrafos desde la antigüedad, no podemos limitarla a un concepto breve que nos habla de manera general del mundo habitado, sino como la interpretación que cada cultura hace de su mundo conocido, de su territorio, y que es representado de las más diversas maneras. Ambas discusiones perecen pertinentes dentro del campo de estudio de la historia con perspectiva global, sobre todo a la luz de las explicaciones alternativas que algunas obras como las que hemos citado ofrecen sobre ese mundo que al parecer no fue tan distinto al actual.

\section{La Longue durée en la historia global}

Escribir historia implica adoptar y generar un método específico que estructure de manera coherente el abordaje de nuestro objeto de estudio. En la composición de este método, el historiador se enfrenta a la elección determinante de la escala temporal y espacial desde la cual se mira el pasado. En este sentido, ambas escalas han sido un paradigma debatido dentro de la disciplina histórica, especialmente el de la escala temporal de la larga duración, estrategia metodológica utilizada por Fernand Braudel hace ya más de sesenta años en su extensa obra El Mediterráneo en tiempos de Felipe II. $^{16}$

\footnotetext{
${ }^{16}$ Fernand Braudel, El Mediterráneo y el mundo mediterráneo en la época de Felipe II (México: Fondo de Cultura Económica, 1987 [1949]).
} 
Ahora bien, fue hasta Histoire et science sociale: la longue durée, escritos publicados en 1958, donde Braudel propuso y desarrolló de manera más profunda el concepto metodológico de la larga duración. ${ }^{17}$ Para él, escribir sobre el pasado adoptando dicha escala temporal, significa pensar la historia más allá de los acontecimientos políticos y militares de corta duración, aquellos que han sido precisamente el principal nutriente de la historia política o événementielle de las naciones durante la última centuria. La larga duración entonces abarcaría un rango temporal de varias décadas, incluso más de un siglo, donde los eventos, políticos, por ejemplo, se encuentran insertos dentro de una serie de estructuras que se transforman de manera lenta en el tiempo, casi imperceptible.

Sin embargo, toda elección metodológica contiene sus particularidades, sus ventajas y sus riesgos. Para Braudel y otros historiadores, escribir historia desde tal perspectiva temporal significaría el establecimiento de un diálogo multidisciplinario con otras ciencias sociales. Esto redundaría, por una parte, en traer al seno de la disciplina histórica una serie de beneficios epistemológicos y metodológicos provenientes de otras ciencias sociales, y, por otra, una cierta aceptación y validación del quehacer historiográfico en el concierto de las otras ciencias que producen conocimiento. Desde nuestra perspectiva, tal es el caso de las obras ya citadas de K. Pomeranz, W. McNeill y J. Diamond. Todas ellas han adoptado dentro de su estrategia metodológica la escala temporal de la larga duración, y al mismo tiempo, estas tres obras se han nutrido de categorías analíticas, modelos e interpretaciones provenientes tanto de otras ciencias sociales como de las llamadas ciencias duras o naturales. Sin embargo, y como veremos a continuación, al entrar en las áreas de solapamiento entre la historia y las otras ciencias también se corre el riesgo de generar ciertas explicaciones de corte determinista, sobre todo si estas se encuentran demasiado apoyadas en los supuestos y las categorías de ciencias tan distantes como la biología, la climatología, e incluso la vertiente más determinista de la geografía.

\section{Solapamientos interdisciplinarios}

En The Great Divergence, el historiador Kenneth Pomeranz realiza una aproximación interdisciplinaria a los estudios históricos acerca de los orígenes del actual estado de riqueza de la Europa occidental -muy diferenciada de la mayor parte de las regiones mundiales estructuradas en torno al modelo de producción capitalista-, y que ha ocupado el análisis de diversos historiadores y científicos sociales. Estos han centrado su atención, sobre todo, en dos cuestiones fundamentales: en primer lugar, se preguntan sobre el origen de esa riqueza y de su relación directa con el gran proceso de la Revolución industrial experimentado en los países del noroeste de Europa a partir de la segunda mitad del siglo XVIII -y más vertiginosamente durante el siglo XIX-. Este periodo en la historia económica de la región es mejor conocido entre sus estudiosos como "la gran divergencia", debido a sus implicaciones sobre el desarrollo económico que, a partir de ese proceso histórico, diferenciaron el mundo entre unas regiones más ricas que otras.

\footnotetext{
${ }^{17}$ Fernand Braudel, “La larga duración”, en Id., Las ambiciones de la historia (Barcelona: Crítica, 2005 [1958]).
} 
Si se acepta la tesis de una divergencia económica a partir de la Revolución industrial, se pueden leer una serie de cuestionamientos focalizados en las condiciones que generaron este gran fenómeno de industrialización y sobre por qué surgió específicamente en la región noroccidental europea -y más aún, en la Inglaterra del siglo XVIII-. A este respecto la historiografía que ha dominado la discusión sobre el tema, y que es citada por Kenneth Pomeranz, tiene como sesgo principal el eurocentrismo, fundamentado principalmente en las ideas civilizatorias, culturalistas e institucionalistas. Dichas explicaciones eurocentristas indican que los factores determinantes en la génesis de la Revolución industrial es posible rastrearlos en ciertas condiciones pre-existentes y excepcionales inherentes a la sociedad europea desde muchos siglos atrás. Tales factores incluirían desde los modelos y la política económica en sus diferentes etapas ligadas al control institucional, hasta las pautas culturales de consumo y los grandes cambios sociopolíticos generados - por mencionar uno solo- a partir de la Reforma protestante. Cabe mencionar que este mismo argumento eurocentrista, citado y desechado por Pomeranz, es muy cercano al que la historiadora Abu-Lughod intenta desechar en Before European Hegemony.

Ahora bien, en ese contexto, la obra de Kenneth Pomeranz tiene como objetivo principal debatir el citado discurso eurocentrista a través de una nueva propuesta de larga duración sobre las condiciones que generaron la gran divergencia mundial a partir de la Revolución industrial. Esta propuesta tiene dos ideas centrales que a nuestro parecer el autor logra desarrollar de manera convincente, objetivo logrado en buena medida debido al uso y apropiación de categorías, conceptos y modelos, provenientes de otras ciencias sociales como la economía, la geografía y la demografía.

La primera de estas ideas es demostrar que, previamente al desarrollo de la Revolución industrial en la Europa noroccidental -y más en concreto en Inglaterra-, dicha región compartía enormes similitudes con el este de China, esto es, con la cuenca del río Yangtsé. Estas similitudes las encontramos en el desarrollo de los estándares de vida en sus respectivas poblaciones durante la época, en las formas de control y uso agrícola del territorio, en los hábitos de producción y consumo de alimentos, así como en la esperanza de vida, indicadores todos ellos elaborados por el autor a través de un exhaustivo trabajo comparativo basado en herramientas metodológicas de la economía y la estadística descriptiva.

A este respecto cabe señalar que aun cuando en algunos trabajos historiográficos previos al de Pomeranz ya existían comparativas entre estas dos regiones -e incluso entre Japón y la India-, dichos análisis habían sido construidos con el fin de mostrar el tipo de polarización que servía como aval para la tesis de la excepcionalidad de la cultura y el pensamiento europeo hasta el siglo XVIII. Sin embargo, el análisis comparativo de Pomeranz muestra todo lo contrario en términos del desarrollo humano y económico sobre lo que existía entre estas dos regiones interconectadas históricamente. Es decir, que hasta cierto punto ambas se habían desarrollado a través del tiempo de manera no tan distinta a como se había pensado hasta el momento. Con este precedente sobre las similitudes entre ambas regiones, el autor demuestra que las supuestas condiciones pre-existentes para la 
Revolución industrial europea también se encontraban dadas en la región este de China. Sorteaba así la tesis eurocentrista y allanaba el camino para exponer su segunda propuesta central para la construcción de un nuevo paradigma sobre la gran divergencia desde la perspectiva global y de la larga duración.

En esta segunda propuesta, Pomeranz dedica su análisis historiográfico a sostener dos tesis principales sobre los factores que incidieron en el desarrollo de la Revolución industrial en la Inglaterra del siglo XVIII y XIX. La primera de ellas se encuentra fundamentada en el giro dado por Inglaterra en el aprovechamiento del carbón como combustible para el funcionamiento de las tecnologías proto-industriales. Con ello se dejaba atrás el uso de la madera y la fuerza animal como fuente principal para la generación de energía. A diferencia de la región este de China, en la Gran Bretaña los recursos carboníferos se encontraban en abundancia y muy cercanos a los primeros centros de producción que los consumían, por lo tanto, su transportación era mucho menos costosa y complicada. En China, las principales minas de carbón se encontraban a gran distancia de los centros de producción, al norte del Yangtsé. Un factor geográfico que finalmente limitó el desarrollo de nuevos patrones económicos y tecnológicos, el cual les hubiese permitido superar los supuestos maltusianos de la demografía.

Por otra parte, Pomeranz lanza su propuesta más elaborada acerca del segundo proceso determinante en el desarrollo de la Revolución industrial inglesa. Este proceso se encuentra definido, en primera instancia, por la fortuna de los europeos de haber llegado al continente americano. Específicamente en el caso de Inglaterra, estableciendo colonias a partir del siglo XVII en la costa noreste del continente americano y en las islas del Mar Caribe.

Ahora bien, a partir de la producción e importación de insumos energéticos como el azúcar, el café, el arroz, entre otros alimentos, así como con la explotación de recursos a través de la mano de obra esclava en estos territorios, fue posible con el tiempo comenzar a sustituir en Inglaterra ciertas actividades ligadas a la producción agrícola, así como la mano de obra que trabajaba la tierra. En estas condiciones fue posible también romper con los supuestos maltusianos del equilibrio ecológico entre la producción de alimentos y el crecimiento de la población, para pasar a las actividades de mano de obra industrial en los centros de producción ingleses. Esto generó una economía de escala que articulaba, por una parte, la producción agrícola, la explotación y circulación de la plata de la nueva periferia europea en las colonias americanas, así como el algodón de la India, que permitieron generar otro tipo de actividades económicas y tecnológicas en Inglaterra, las cuales desbordaron hacia el desarrollo de una revolución industrial bien sólida durante el siglo XIX.

A partir de estas dos tesis centrales y con el presupuesto comparativo entre Europa y Asia en los siglos previos a la Revolución industrial, Pomeranz demuestra cómo pudo haberse estructurado de manera temprana, y casi contingente, el proceso divergente de ambas regiones, lo cual tuvo grandes repercusiones a escala global durante los dos siglos posteriores. 
Para discutir las dos tesis centrales desarrolladas por el autor diremos que entre ellas es posible encontrar solapamientos con otras ciencias sociales. Por una parte su propuesta parece nutrirse de las explicaciones ofrecidas por diversas teorías espaciales, desarrolladas durante toda la primera mitad del siglo XX por algunos geógrafos alemanes, como la “teoría de la localización” de los recursos respecto a los centros de producción industrial propuesta y desarrollada por el geógrafo economicista Alfred Weber en 1929-, así como la “teoría del lugar central” de Walter Cristaller. ${ }^{18}$ Por otra parte también es posible rastrear la influencia de los modelos de generación de las "economías de escala entre territorios". Ambas perspectivas se han desarrollado desde el campo de la geografía económica y los estudios regionales comparados, los cuales toman en cuenta frecuentemente la distribución territorial de los recursos, la localización y grado de desarrollo tecnológico de los centros de producción industrial, así como el impacto de estos factores en la generación de economías bien diferenciadas entre distintas regiones. ${ }^{19}$ Elementos que sin duda es posible reconocer en la segunda tesis de Pomeranz, la cual analiza las complejas redes de comercio y explotación inglesas establecidas con sus colonias a partir del siglo XVII, donde además encontramos desarrollados los supuestos demográficos propuestos por Robert Malthus.

\section{El determinismo geográfico}

La discusión sobre el grado de influencia del medio ambiente -a veces mal llamado medio geográfico- en los asuntos pasados y presentes de las sociedades humanas, todavía hoy sigue teniendo gran pertinencia. Aún es más: es un hecho central dentro del campo de las ciencias sociales. Particularmente en el caso de la historia, la perenne pertinencia de esta discusión parece descansar en los esfuerzos de diferentes grupos de historiadores, a través de sus respectivos sub-campos de investigación, por integrar a la disciplina dentro de alguno de los paradigmas sobre los cuales ha oscilado la profesión.

Por un lado el paradigma de las ciencias sociales, donde a la historia -como ya hemos mencionado al principio de esta apartado-, se le abre la posibilidad de nutrirse de los métodos y la epistemología de otras ciencias; y donde sobre todo es más fácil hallar aceptación en el uso de ciertas categorías medioambientales que se utilizan como factores explicativos, cuando no determinantes, de ciertos procesos históricos. Vinculación que se produce a partir del préstamo que toman estas ciencias sociales de sus primas hermanas, las ciencias naturales. Por otra parte, algunos historiadores creen en la pertinencia de acercar la historia hacia el terreno de las humanidades en la medida en que su objeto de estudio está principalmente determinado por las acciones y la conciencia de las personas a través del tiempo. En el caso de la historia global esta discusión parece tener singular relevancia. Este hecho se ve con mayor claridad cuando en estos trabajos escritos desde tal perspectiva se proponen explicaciones sobre el desarrollo histórico de las diferentes sociedades a escala global, tomando como ejes explicativos elementos medioambientales como las condiciones

\footnotetext{
${ }^{18}$ Rocío Rosales, “Geografía Económica”, en D. Hiernaux y A. Lindón (dirs.), Tratado de Geografía, 129-46.

19 Ricardo Méndez, Geografía Económica. La lógica espacial del capitalismo global (Barcelona: Ariel, 1997), Caps. 1 y 2.
} 
climáticas, la edafología, o las formas de traslado, incubación y transmisión de gérmenes y enfermedades a través del territorio. En ese sentido es posible hacer un análisis al respecto sobre las obras de William McNeill y Jared Diamond.

En el caso de Plagues and Peoples, William McNeill relata una sintética historia a escala global y de larga duración sobre el desarrollo de la especie y la sociedad humanas en su estrecha relación con el medio ambiente, específicamente, con las enfermedades y parásitos de los que hemos sido huéspedes desde nuestros orígenes pre-humanos en el África subsahariana hasta las complejas relaciones que se mantuvieron hasta bien entrado el siglo XX de nuestra era. El acento de esta obra se encuentra puesto en las relaciones particulares que se han establecido entre las sociedades humanas y las diversas enfermedades que las han aquejado, poniendo especial atención en las determinantes del medio geográfico y la cultura material como factores que han desempeñado un papel modelador del equilibrio ecológico entre humanos y parásitos durante miles de años. Según la propia tesis del autor, este equilibrio ecológico es clave para comprender los diferentes momentos en la historia de la sociedad humana, dado que dicho equilibrio ha determinado una serie de condiciones sociales necesarias para la ocupación de las más diversas regiones del mundo; el crecimiento de la población mundial; el desarrollo de la tecnología para la sustentación alimentaria de la mismas; así como el origen y rumbo de las relaciones de poder y dominación entre pueblos, civilizaciones e imperios de todo el mundo.

En esta obra, dice el autor, se aborda una perspectiva poco conocida y valorada en los estudios históricos, abriéndose un campo olvidado durante muchas décadas sobre la relevancia, a veces rotunda, de la historia de las relaciones milenarias entre la sociedad humana y las enfermedades que ha portado consigo en su travesía a escala global. En esta obra, McNeill propone establecer paralelismos entre las relaciones microparasitarias y las relaciones sociales de poder dentro y fuera de la organización política, económica y militar de los pueblos, las civilizaciones y los imperios.

Sobre el trabajo de Jared Diamond, Guns, Germs and Steel, podemos decir que se trata de una extensa obra en una tónica muy similar a la MacNeill, especialmente porque en ella uno de los ejes principales para el análisis del desarrollo histórico de las sociedades a escala global es el papel de los gérmenes -específicamente, las enfermedades que los primeros animales domesticados por el hombre le transmitieron a este e hicieron de él una especie más fuerte en diversos contextos y en ciertas épocas-. Sin embargo, esta condición inmunológica no existió para todas las sociedades del planeta de la misma forma ni al mismo tiempo. Jared Diamon ofrece una explicación sobre los orígenes de esta ventaja inmunológica en ciertos grupos de humanos que lograron establecerse en algunas zonas del planeta donde las condiciones climáticas y edafológicas eran las más propicias, tanto para la existencia de las especies animales domesticables que les transmitieron estos gérmenes, como para el desarrollo de la agricultura basada en la fuerza de trabajo de los mismos. Estas condiciones les llevarían con el tiempo al desarrollo e integración de formas de apropiación y modelaje del territorio y de sus recursos que les permitirían llegar a un punto en el que podrían dedicarse a la generación de tecnologías como el acero y las armas. 
Factores que, a lo largo de miles de años, redundarían en condiciones más favorables para para ejercer la dominación militar, poblacional, económica y política a escala global.

En ambos casos las obras abordan el estudio de fenómenos históricos que tuvieron difusión a través de extensiones territoriales globales. En ellas los factores humanos y sociales no parece ser suficientes para dar salida a las explicaciones de estos hechos a escala global. En tal contexto los autores introducen el uso de la categoría de "medio ambiente”, en sus distintas formas y dimensiones, para añadir complejidad y coherencia a su análisis. En ambas obras encontramos la idea central del desarrollo de una cultura material de las sociedades humanas en consonancia con el medio ambiente -desde sus orígenes migrantes en África central y hasta nuestros días-, y a través de la cual hemos logrado modelar las condiciones medioambientales a escala mundial. Estas transformaciones han sido solo posibles gracias a los intercambios biológicos que durante miles de años -y a lo largo de todas las regiones del mundo- los seres humanos hemos llevado a cabo en diferentes momentos de la historia. Estos intercambios biológicos, sobre todo, se refieren al traslado e inserción de diversas especies de plantas, animales y enfermedades en prácticamente todas las regiones biogeográficas donde hemos tenido algún tipo de asentamiento y desarrollo de nuestra cultura. Procesos que hoy muestran una difusión de carácter global.

Si bien ambos trabajos se interesan por demostrar que el medio ambiente juega un papel relevante dentro del curso de la historia humana, desde nuestra perspectiva tanto McNeill como Diamond estarían muy cerca de argumentar que ese factor medioambiental ha sido el determinante en el curso de nuestros caminos históricos como sociedad global. Aceptando este posible determinismo como plausible, creemos que lo que valdría la pena poner en discusión sería la orientación que toma nuestra relación como sociedad con el medio ambiente a través del tiempo. Es decir, que como hemos visto en MacNeill y Diamond, tal relación quizás en algún momento, hace decenas de miles de años, fue vertical y las sociedades humanas nos encontrábamos debajo, oprimidas por las condiciones determinantes del medio ambiente y por los factores biológicos -algo que sin duda no está muy alejado de los paradigmas actuales de las ciencias naturales-. Sin embargo, dentro del relato y el análisis de la historia humana, habría que pensar esa verticalidad de otra manera.

La propuesta giraría entonces en torno a un equilibrio dado por la confluencia de los factores históricos y sociales con los medioambientales. Esto daría como resultado una relación horizontal con transferencias continuas entre ambos. En esa relación horizontal la historia humana se encontraría, por una parte, ligada a un medio ambiente transformado a lo largo de miles de años por nuestra cultura, y por otra, ligada y quizá más prefijada por nuestras relaciones sociales.

\section{Conclusiones}

La tradición de la perspectiva global en la escritura de la historia tiene orígenes similares a los de la disciplina misma; sin embargo, durante varias decenas de años la llamada global history ha vivido a la sombra de las tradiciones historiográficas que se 
fueron desarrollando con mayor fuerza a partir del siglo XIX -entre ellas la historia política y la social-. Solo a finales del siglo XX, y en lo que va del XXI, la historia con perspectiva global ha comenzado a constituirse como una tradición aceptada dentro de la disciplina, pero también entre las instituciones académicas. Universidades y centros de investigación han demostrado durante las últimas décadas un interés genuino por esta forma de abordar los estudios históricos. Esto se ha visto reflejado, sobre todo, en una mayor apertura de espacios y presupuestos para la investigación dentro de este campo especializado de la historia.

Son diversas las razones por las cuales la perspectiva global sobre el estudio del pasado no logró legitimarse y consolidarse de manera importante durante el siglo XX -un periodo en el cual sí se legitimaron la mayoría de los paradigmas de la disciplina-, tanto en términos de su objeto de estudio, como en el método que desarrollan durante sus investigaciones. Algunas razones sobre este distanciamiento histórico obedecen precisamente tanto al objeto como al método de la perspectiva global. En el caso del objeto de estudio, al ser este por naturaleza mundial, en muchas de las obras que lo adoptan frecuentemente suele perderse de vista el detalle de las historias nacionales, regionales y locales, las cuales han sido los pilares tradicionales de la historiografía previa. Esto ha provocado a lo largo de años que la historia global sea considerada por muchos historiadores tradicionales como un sub-campo que produce literatura popular para la difusión de la historia general del mundo. Por otra parte, la historia global se ha enfrentado a la dificultad de adoptar un método específico, tanto en sus fuentes como en el análisis, debatiéndose siempre entre la tradición y el eclecticismo. De hecho, una de las críticas más comunes al método utilizado por la historia global es el hecho de sus constantes coqueteos con otras categorías, conceptos y modelos explicativos que, como hemos visto, provienen de las ciencias sociales y naturales. ${ }^{20}$

Pese a todo lo comentado, la perspectiva global en la escritura de la historia aún es un campo susceptible de ser explorado y alimentado a través de las más diversas experiencias investigadoras. La discusión interna -siempre positiva para su desarrollo- acerca de las diferencias metodológicas entre la historia comparativa, internacional, mundial o global, seguramente seguirá existiendo entre quienes están interesados en romper con la arraigada perspectiva de las historias nacionales como fuente de análisis ${ }^{21}$ También se debe reconocer abiertamente que el cambio de escala espacial y temporal muchas veces implicará una pérdida de detalle sobre los territorios e historias locales.

Dicho lo anterior, el presente artículo partió de la premisa de una crítica hacia el interior del campo de la historia global, reconociendo que existen importantísimas cuestiones metodológicas y epistemológicas por resolver. Estas, quizá, como hemos intentado esbozar a lo largo del trabajo, se podrían revisar a la luz de las propias

\footnotetext{
${ }^{20}$ Jürgen Osterhammel, "World History”, en Daniel Woolf (ed.), Oxford History of Historical Writing, vol. 5 (Oxford: Oxford University Press, 2011), Cap. 5.

${ }^{21}$ C.A. Bayly y otros, “AHR. Conversation: On Transnational History”, The American Historical Review, vol. 111, 5 (2006): 1441-64.
} 
experiencias historiográficas que dialogan con otras disciplinas. Todo dependerá de la apertura y solidez que exista dentro de la misma Historia, como ciencia social o como parte de las humanidades. Lo cierto en todo esto es que, como sucedió hace algunas décadas con la incursión hacia la microhistoria, la global history presenta serios retos metodológicos, epistemológicos y hasta ontológicos, sobre la naturaleza del oficio del historiador y la historiadora en los tiempos actuales.

Las obras y reflexiones que hemos presentado a lo largo del artículo han servido como fuente de análisis crítico acerca de aquellas dificultades a las que se enfrenta la historia global en su intento por aprehender temporalidades y territorios de gran escala. Además de esta cuestión, los autores de las obras nos muestran la importancia que puede tener el acercamiento hacia las fronteras con otras ciencias sociales. En dichas áreas colindantes muy probablemente se encontrarán vitales aportaciones metodológicas y epistemológicas. Y ahí, donde muchas veces las historias globales pierden de vista las decisiones contingentes de los individuos, se podrán introducir de manera equilibrada y de cara al análisis del pasado los factores medioambientales, geográficos o biológicos que enriquezcan la perspectiva global de la historia.

Finalmente, parece pertinente que la discusión sea llevada al seno del campo de la historia global, no solo de manera teórica o retórica, sino como reflexión necesaria dentro de las mismas historiografías escritas desde esta perspectiva. Aunque frecuentemente la diversidad nutre a las disciplinas y a las ciencias, en el caso de la historia global esta deberá evitar orientar hacia el determinismo las explicaciones sobre los grandes temas históricos de las sociedades humanas. Si ese fuese el caso, la historia global que ha heredado una parte fundamental del pensamiento de Fernand Braudel estaría al mismo tiempo negando el legado de sus predecesores, Paul Vidal de La Blache y Lucien Febvre, quienes fueron los primeros geógrafos e historiadores en mostrar la importancia del posibilismo dentro del mundo natural modelado por las manos y la cultura de los pueblos.

\section{Profile}

Francisco Navarro es doctorando en Geografía en la Universidad Complutense de Madrid, España. Obtuvo una Maestría en Historia Internacional por el Centro de Investigación y Docencia Económicas y la Licenciatura en Geografía Humana por la Universidad Autónoma Metropolitana, ambas en la Ciudad de México. Ha realizado investigaciones en México, Perú e Italia en torno a la geografía urbana, el paisaje, la historia del territorio, historia urbana, arquitectura y patrimonio.

Francisco Navarro is working for his PhD in Geography at the Universidad Complutense of Madrid, Spain. He obtained a Master's degree in International History at the Centre for Research and Teaching in Economics, and graduated in Human Geography at the Universidad Autónoma Metropolitana, both un México city. He has carried out research in 
Mexico, Italy and Peru with projects on urban geography, landscape, history of the territory, urban history, architecture, and heritage.

Fecha de recepción: 15 de mayo de 2017.

Fecha de aceptación: 19 de septiembre de 2017.

Publicación: 31 de diciembre de 2017. 